\title{
ANKYLOSING SPONDYLITIS IN WOMEN
}

\author{
BY \\ F. DUDLEY HART AND K. C. ROBINSON \\ From Westminster Hospital, London
}

In the 12 years since the Rheumatism Clinic was started at Westminster Hospital a special interest has been taken in ankylosing spondylitis, and although male patients have predominated it has become evident that this is an important cause of skeletal pain and disability in women also. Few series describing the condition as it affects women have been published. Tyson, Thompson, and Ragan (1953) reviewed sixty cases observed during the previous 20 years at the combined arthritis clinics of the Presbyterian and New York Hospitals; they noted a rather more frequent involvement of the cervical spine and symphysis pubis in women, and they thought that the course of the arthritis was more benign, but they concluded that on the whole there was little difference in the clinical picture between the sexes. Forestier, Jacqueline, and Rotes-Querol (1956) referred to fifty female patients; they also observed that spinal deformity was less frequently seen and was less severe than in men, but they did not consider that there were enough differences to justify the description of a female form of the disease.

The present report is an analysis of the thirty female patients who have attended the clinic in the past 12 years in whom ankylosing spondylitis has been diagnosed. Several of them have been observed over several years; a full clinical examination has always included a note on the spondylometer reading, and on the chest expansion, as this is reduced at an early stage in the disease (Hart and Maclagan, 1955). Radiographs of the sacro-iliac joints were taken in all cases, and other parts of the skeleton were $x$-rayed when there were clinical indications.

\section{Clinical Features}

Sex Incidence. -The ratio has generally been considered to be about 10 men to one woman; in recent years a ratio of nearly 5 to 1 has been reported (Blumberg and Ragan, 1956; Wilkinson and Bywaters, 1958). While the present series of thirty female patients has been observed, however, 315 men have attended the Clinic, giving an incidence of $9 \cdot 5$ women to 100 men. This figure is given only for what it is worth, since it is clear that in any personal series many irrelevant factors affect the sex incidence; in the present instance the proportion of men is almost certainly increased because a large number of the patients were referred from the Armed Services.

Age at Onset.-This ranged from 13 to 34 years (average 22). This resembles the age at onset in men and confirms that ankylosing spondylitis in women as well as in men is primarily a disease of young adults; it is also a clear point of difference from rheumatoid arthritis.

Family History.-Only one patient gave a history of ankylosing spondylitis in a relative, in this case an uncle; two other patients each had a close relative with rheumatoid arthritis. It has not been possible to examine the relatives of patients and no useful comment can be made on hereditary or familial factors.

Site of Onset.--This is shown in Table I. Pains described as affecting the region of the lumbar spine, sacro-iliac joints, and buttocks were not easily differentiated from one another, and are all included under the first heading (eleven patients).

TABLE I

SITE OF INITIAL SYMPTOM IN THIRTY FEMALE PATIENTS

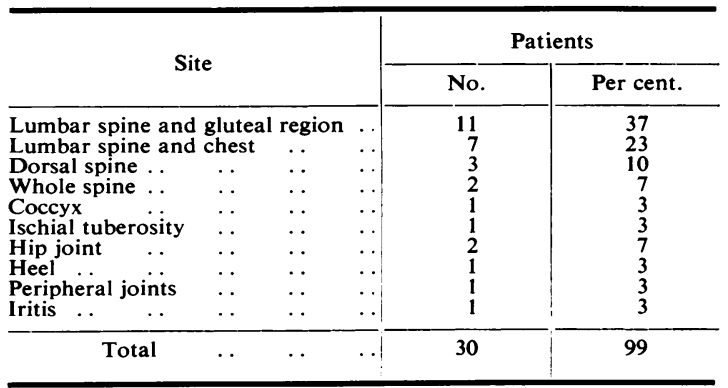


Five patients (17 per cent.) had an extra-spinal onset of pain. Low backache with morning stiffness was the commonest presenting symptom, and pain spreading round the chest especially on coughing was noted as an early symptom in five cases.

Symptomatology.-As the condition progressed other sites were frequently involved, and the cervical spine in particular was often affected; nine patients complained of pain here and four showed radiological changes. This was not, however, noted as an initial symptom, although Tyson, Thompson, and Ragan (1953) found it to be the presenting feature in 5 per cent. of their cases. Pains around the shoulder were also common, being reported by seven patients, but only two had persistent stiffness here, and only one had radiological abnormality (consisting of irregularity of the lateral scapular border with osteoporotic areas above and below the glenoid fossa). In one patient persistent pain with localized tenderness of the left iliac crest was a troublesome symptom.

Case 1, a woman who was first seen at the age of 31 , had a 9-year history of intermittent pain in the right hip, upper dorsal spine, and around the chest. Examination disclosed a stiff spine (spondylometer $35^{\circ}$, chest expansion $\frac{3}{4}$ in.), but her posture was good. A course of radiotherapy (skin dose $1,200 \mathrm{r}$ to the whole spine except the sacral region) gave relief of symptoms. A pregnancy the following year had little effect on the spondylitis and her delivery was uneventful. Subsequently she complained of pain and tenderness on the left iliac crest which was not eased by analgesics. Radiographs failed to show any abnormality here, but she was given further local radiotherapy to the area with relief which has to date been permanent. In the last 8 years she has had some low back pain and stiffness and occasional points of tenderness in the buttocks and on the ribs, but has been able to lead a normal life and has only needed occasional aspirin or compound codeine tablets.

This illustrates the way in which bony tenderness at sites remote from any joint may be a prominent feature of the symptomatology.

\section{Radiological Changes}

For the purpose of comparison the changes in the sacro-iliac joints have been classified into four grades:

I. Ilial sclerosis with or without apparent widening of the joint space; loss of clarity; slight erosions, affecting less than half of one or both sides.

II. More extensive erosions and ilial sclerosis.

III. Partial joint obliteration.

IV. Complete joint obliteration.
Changes in these joints show a very variable rate of progress (see Table II); complete fusion took place in one patient after only 5 years of symptoms; whereas in two other patients only minimal abnores malities were present after 20 years. In one of these last two patients there was extensive paravertebral calcification ("bambooing") in the lumban" spine associated with slight sacro-iliac changes $\vec{D}$

\section{TABLE II}

EXTENT OF SACRO-ILIAC JOINT INVOLVEMENT COM:PARED WITH DURATION OF DISEASE IN THIRTY PATIENTS

\begin{tabular}{|c|c|c|c|c|c|c|}
\hline \multicolumn{2}{|c|}{$\begin{array}{l}\text { Duration of } \\
\text { Disease (yrs) }\end{array}$} & $0-4$ & $5-9$ & $10-14$ & $15-19$ & $\begin{array}{c}20 \text { and } \\
\text { Over }\end{array}$ \\
\hline \multirow{4}{*}{$\begin{array}{c}\text { Grade } \\
\text { of Joint } \\
\text { Involvement }\end{array}$} & 1 & 2 & 2 & 1 & 0 & 2 \\
\hline & II & 2 & 2 & 1 & 1 & 0 \\
\hline & III & 1 & 1 & 1 & 0 & 1 \\
\hline & IV & 0 & 2 & 6 & 1 & 4 \\
\hline \multicolumn{2}{|l|}{ Total } & 5 & 7 & 9 & 2 & 7 \\
\hline
\end{tabular}

Where fusion is complete the outline of the joint can still be seen as a "ghost" joint, at the uppeह end of which there is often a denser point of calci fication, the "star" sign (Fig. 1, opposite).

Sacro-iliac involvement was present in every casêे although occasionally the most advanced radio $\mathbb{Q}$ logical changes were observed elsewhere, while there were still only early sacro-iliac changes. Onङ such case with minimal sacro-iliac abnormality and extensive lumbar paravertebral calcification haș already been mentioned. In another patient the hips were mainly affected.

Case 2, a girl aged 16 years, developed aching and morning stiffness in the hips. The left hip was imo mobilized with skin traction and she was given anti 2 tuberculous chemotherapy; 3 years later this hip was surgically arthrodesed. Later the same year, as pain and stiffness in the right hip increased, this was also immobilized by skin traction and she had a further course of chemotherapy. When she was seen at the clinic ther following year there were only a few degrees of move $\mathrm{N}$ ment in the right hip. A radiograph of the sacro-iliaq joints showed Grade III changes, but a review of thew films taken 2 years after the onset of the spondylitis when the hips were radiologically involved showed onlyo minimal Grade I changes.

This case illustrates the difficulty of early diagnosis 0 when bony and arthritic lesions start in the hips or even more peripherally, and not in the more usua $\mathrm{P}$ sacro-iliac region. Such early hip involvement is 


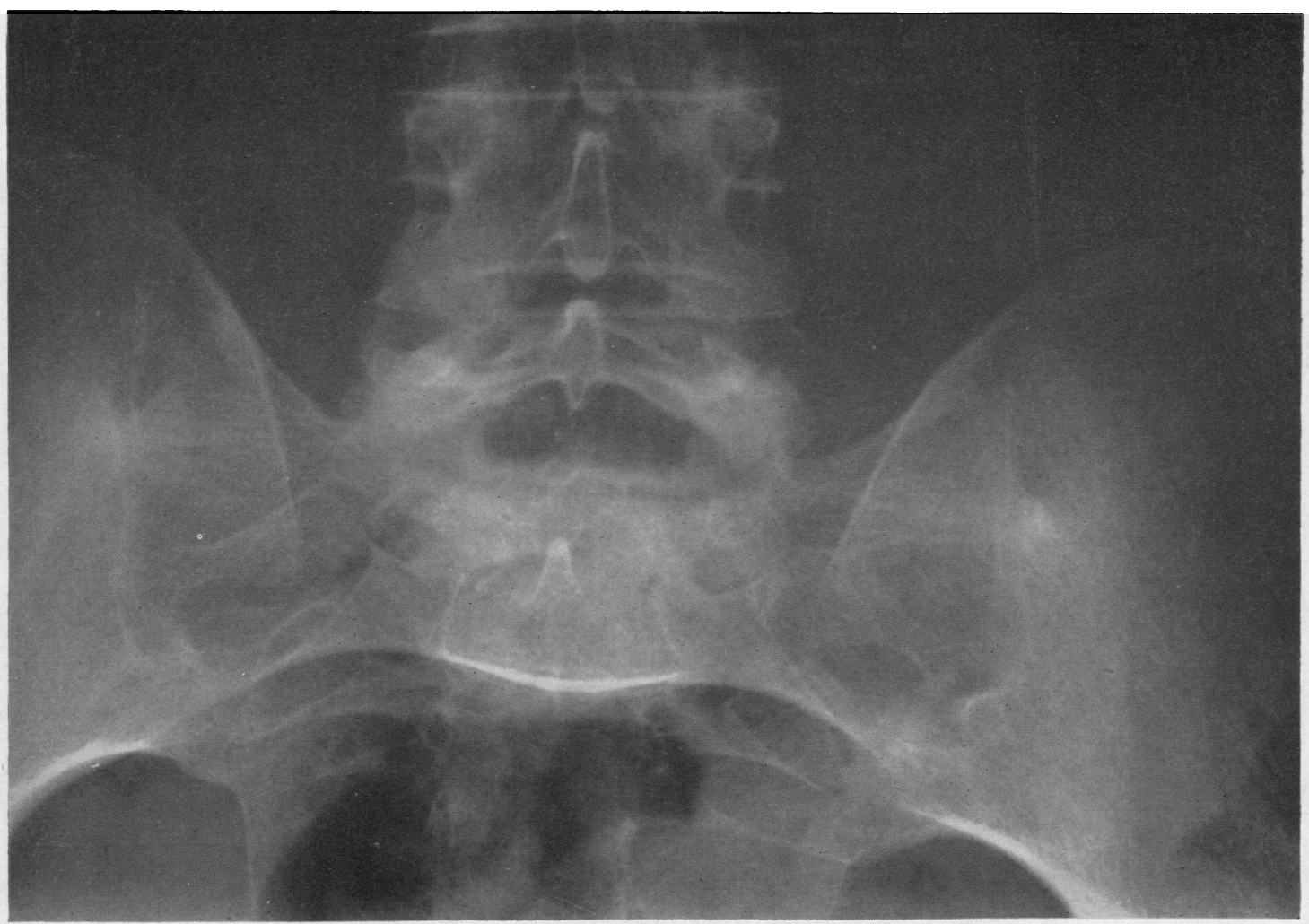

Fig. 1.-Ankylosis of sacro-iliac joints. Note line of "ghost" joints with residual "star" at top of obliterated joint.

not confined to women and has been observed more than once in our male patients; in both sexes bilateral ankylosis occurs rapidly, especially if the patient is immobilized.

The second most common part to be affected radiologically was the lumbar spine, which was affected in twelve patients (Table III).

TABLE III

SITE OF RADIOLOGICAL ABNORMALITY IN THIRTY FEMALE PATIENTS WITH SPONDYLITIS

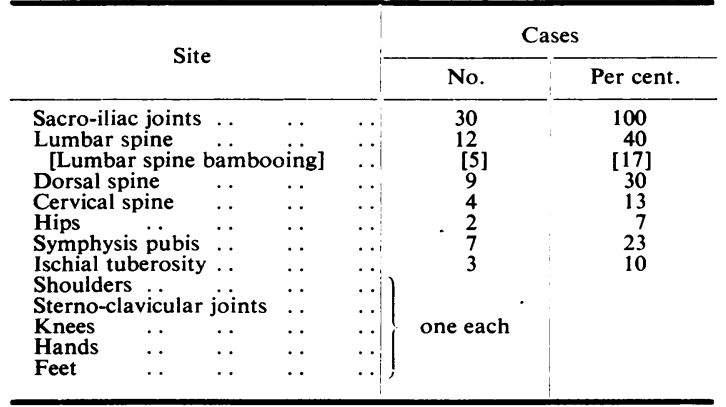

The impression was gained that radiological changes outside the sacro-iliac joints were less frequent than in men. Paravertebral calcification also appeared to be less common in this small series, but it could develop within 5 years of the onset of symptoms. In three patients it was extensive and affected the whole spine (Fig. 2, overleaf).

When the costo-vertebral joint was grossly involved, it gave the appearance of a flared rib (Fig. 3, overleaf).

The development of a massive "bridge" of calcification with no history of trauma was watched in one case by serial films, as it arose between the bodies of L3 and L4 over the course of 2 years (Fig. 4, overleaf).

There did not appear to be in this series an unduly frequent involvement of the cervical spine, but lesions of the symphysis pubis were common (Fig. 5, overleaf).

These consisted of erosions, widening, and sclerosis, and were accompanied in two patients by local tenderness. Painful lesions with radiological changes were also observed at sites away 


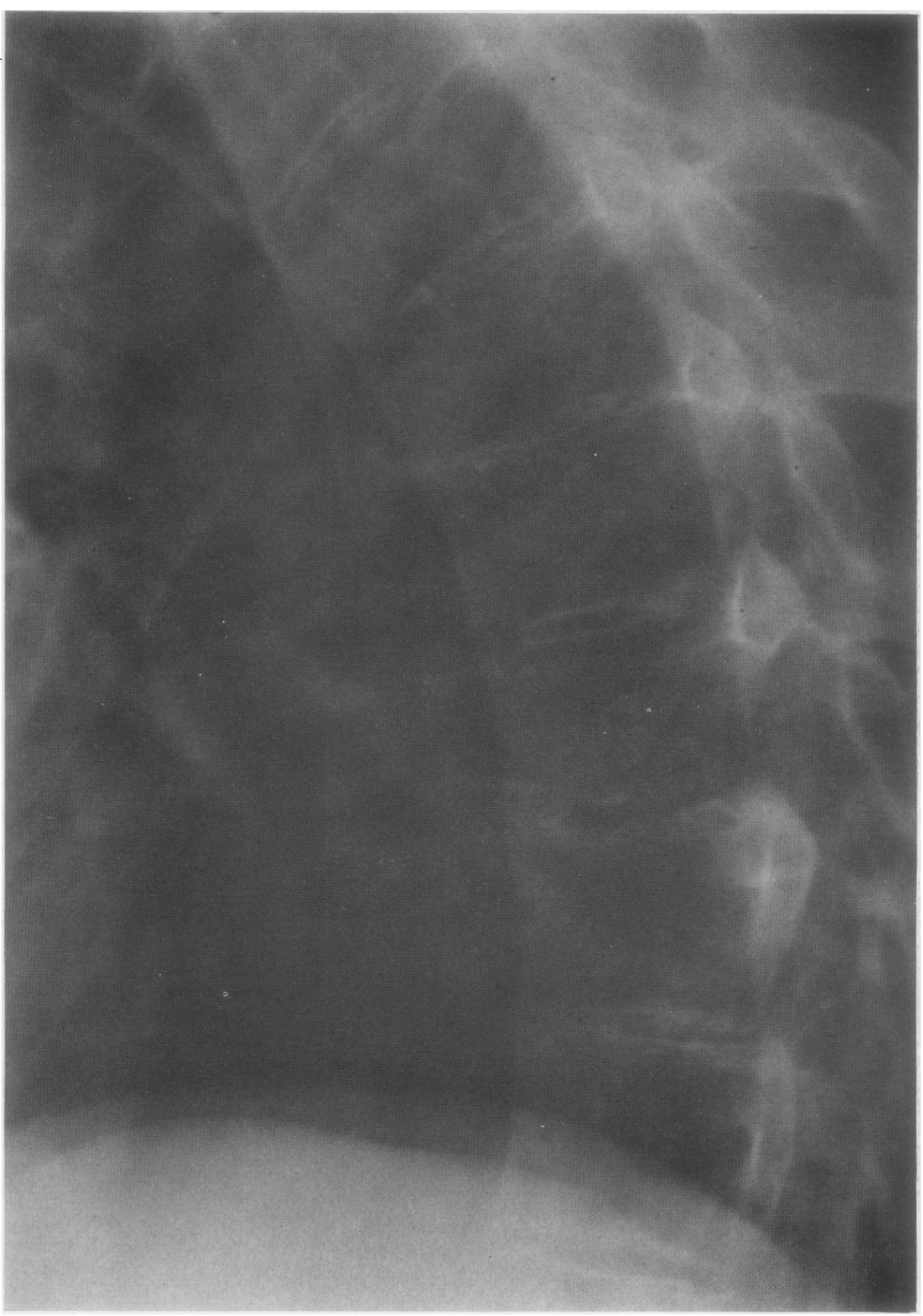

Fig. 2.-Dorsal spine, showing gradual obliteration of anterior margins of disk spaces by paravertebral calcification. 


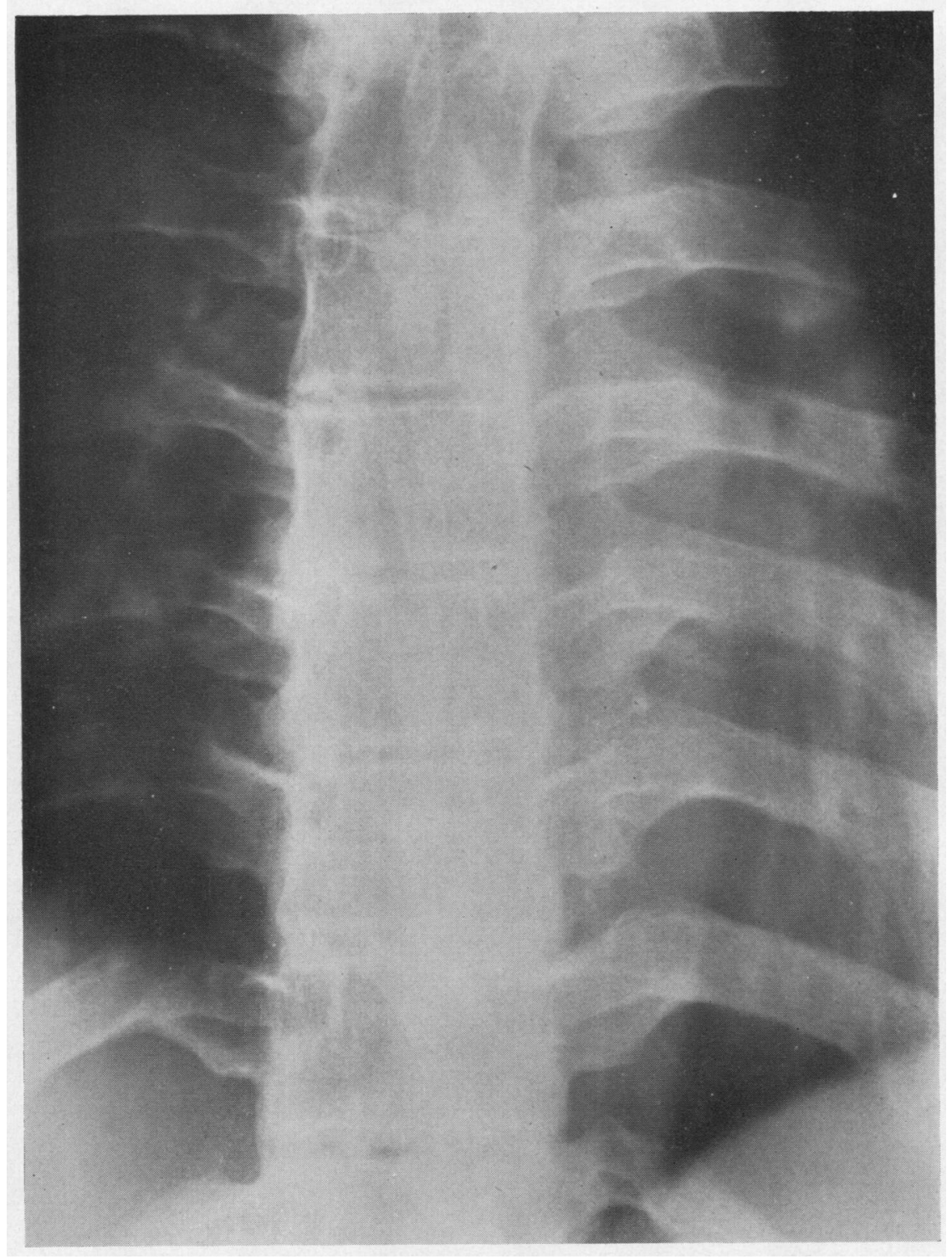

Fig. 3.- "Flared ribs", indicating fusion of rib to vertebral body.

from articular structures; one such patient presented to the orthopaedic department with a persistently painful heel. $X$ ray showed a calcanean spur which was porotic when compared with the adjacent bone. A history was then obtained of low backache for 2 years; spinal movement was good (spondylometer $60^{\circ}$ ), but the chest expansion was only $1 \frac{1}{2}$ in. and the erythrocyte sedimentation rate was raised. There were characteristic $x$-ray signs in the sacro-iliac joints, and the symphysis pubis was also affected. This patient developed her first attack of iritis in the following year. In the one patient who had associated psoriasis there were widespread "feathery" changes around the pelvis 

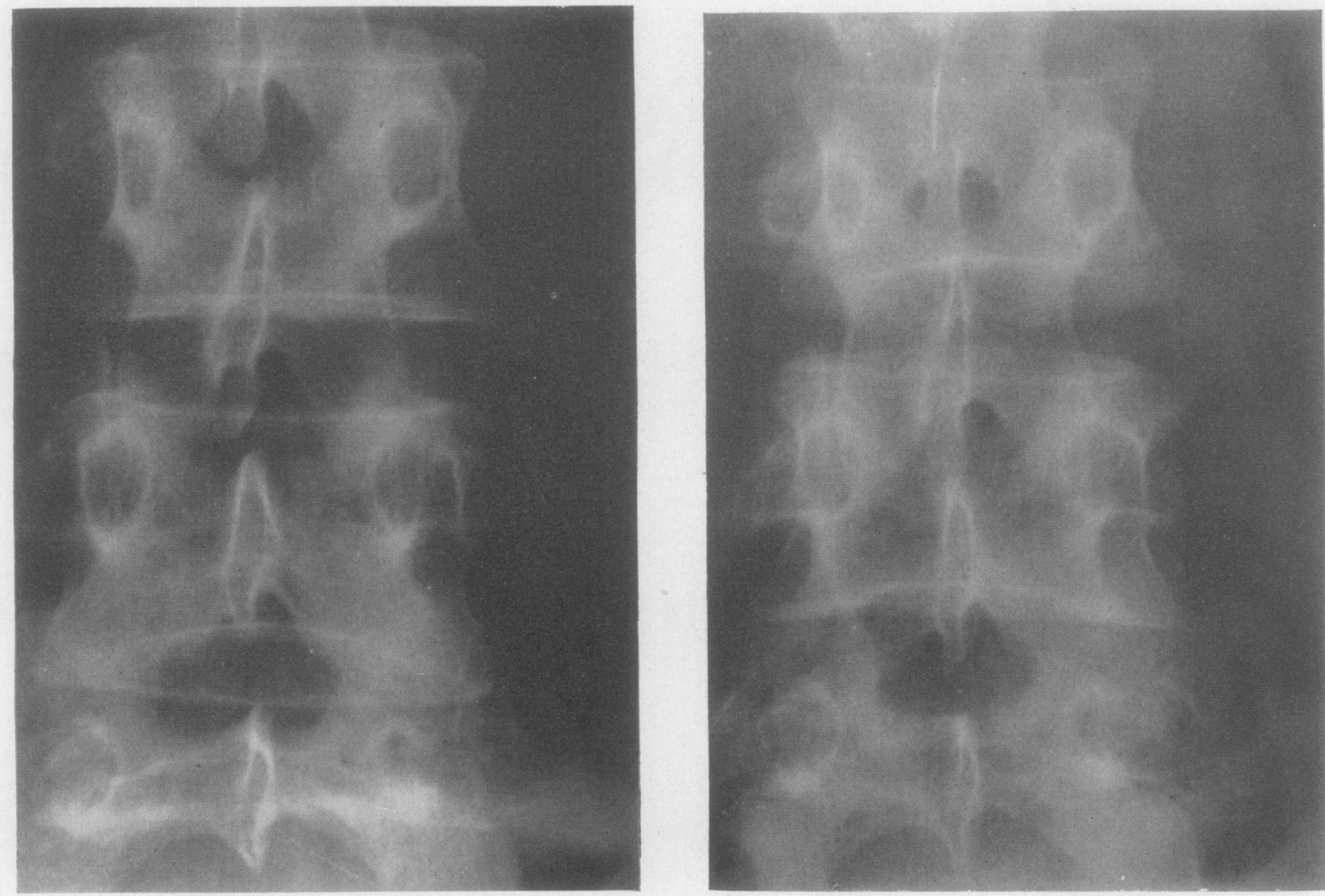

Fig. 4.-Development of coarse bridging between the bodies of Lumbar 3 and $4 ; 1948,1949,1950,1955$.

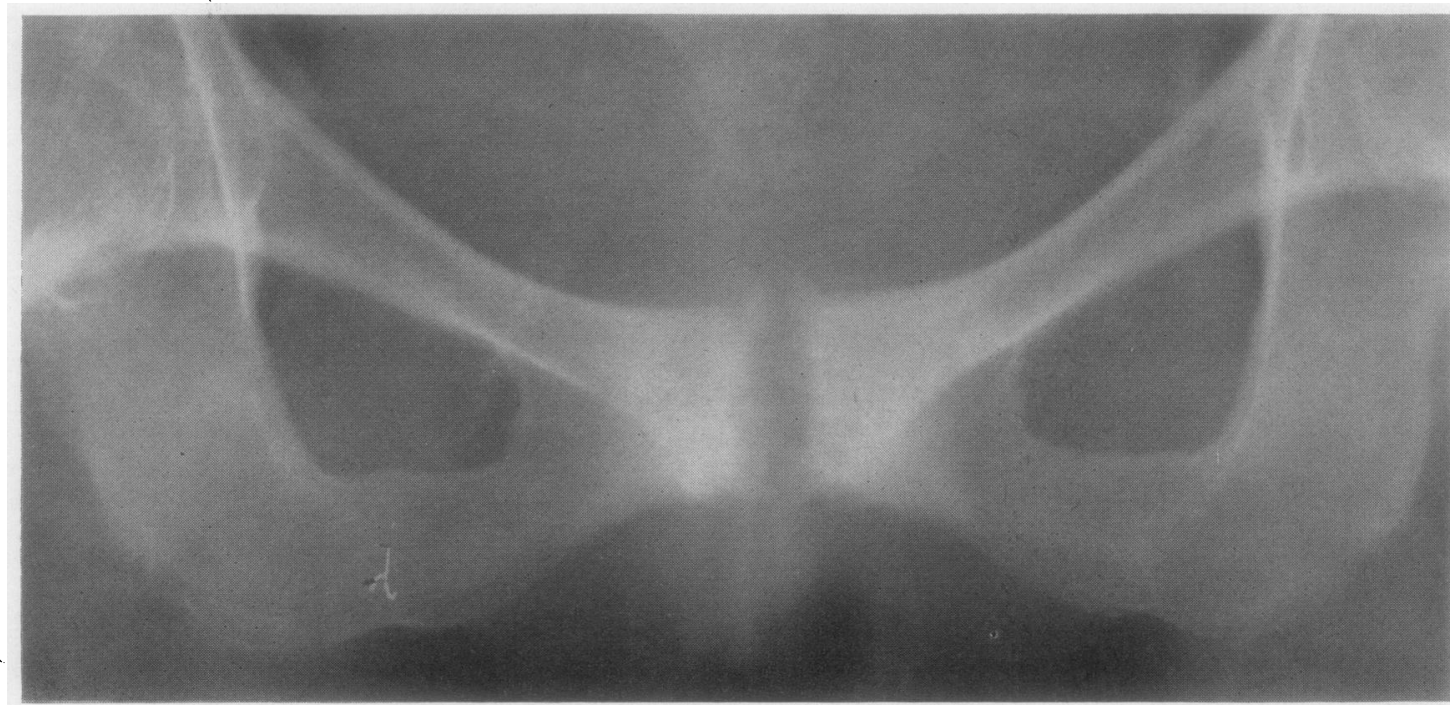

Fig. 5.-Widening, erosion, and sclerosis of symphysis pubis. 

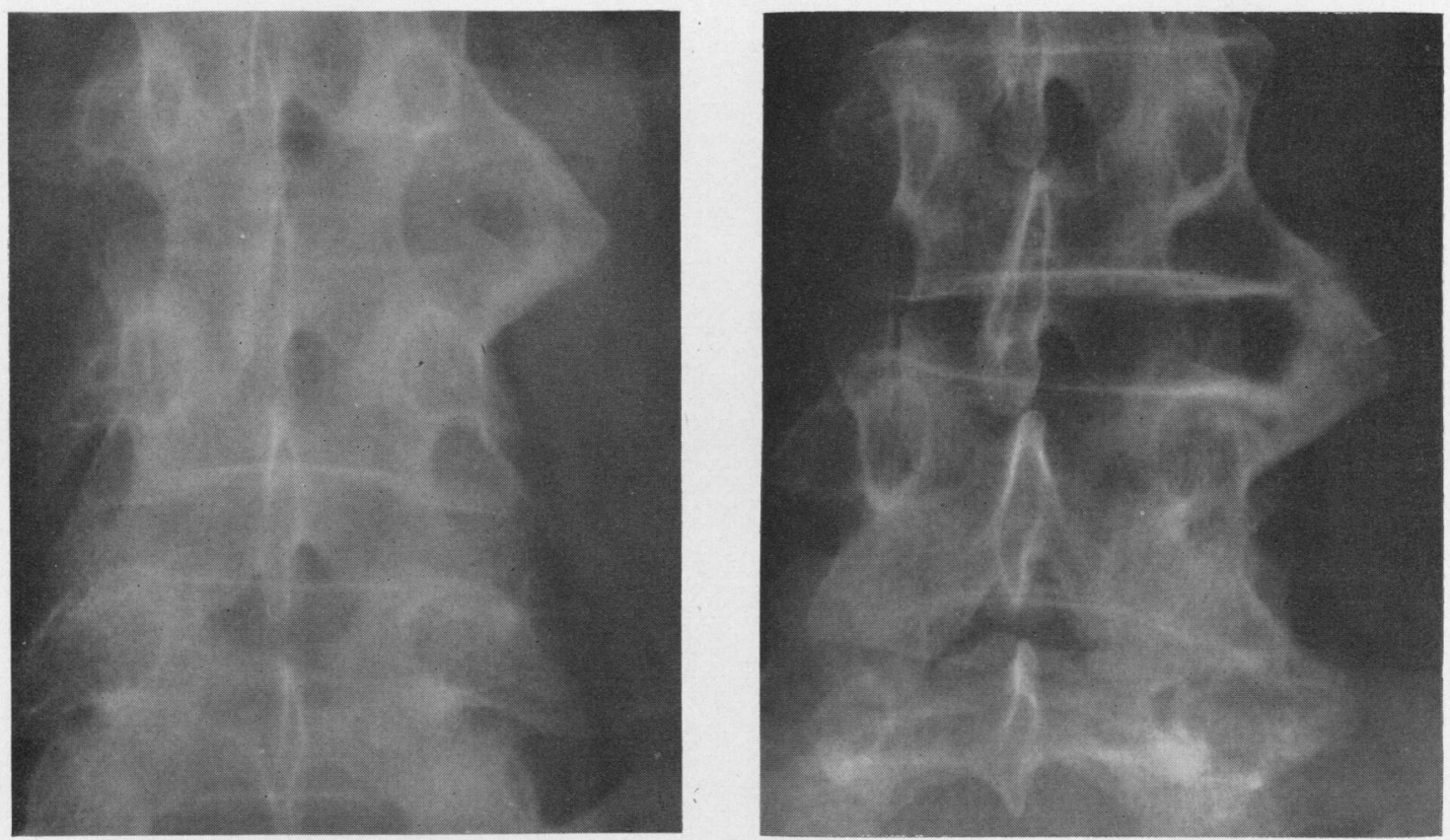

Fig. 4.-Development of coarse bridging between the bodies of Lumbar 3 and 4: 1948, 1949, 1950, 1955.

and extending down on the femora (Fig. 6, overleaf ).

\section{Pregnancy}

Twenty women out of this series of thirty patients were married and fourteen had had one or more pregnancies. None noticed significant aggravation or improvement in the disease during cyesis. The obstetric management in two of them has been reported in detail elsewhere (Hart, Bell, and Organe, 1951); there were no significant complications in the others. Seven said the symptoms of spondylitis were worse after the pregnancy, but no objective alteration was noted, and there was no apparent increase in the progress of the disease. Two said they were improved after the pregnancy and the other five noted no difference. In view of the importance which pelvic infection is claimed to play in the aetiology of ankylosing spondylitis in men (Romanus, 1953), it is interesting that none of the patients gave any history or had any clinical features suggesting such infection. Two patients had minor menstrual irregularities when the spondylitis was particularly active.

\section{Associated Diseases}

Iritis.-This occurred in seven patients. This gives an incidence of 23 per cent., and is similar to that reported by other authors in their combined series of male and female patients (Blumberg and Ragan, 1956; Wilkinson and Bywaters, 1958). In four patients there were multiple attacks; in one the first episode preceded the rheumatic symptoms by 14 years, and it was ultimately the recurrence of the iritis which led to further investigation and the diagnosis of spondylitis.

Other Conditions. - Apart from iritis the following occurred once each: acromegaly, psoriasis, schizophrenia, pulmonary tuberculosis, spinal tuberculosis, and a cauda equina lesion of undetermined aetiology. Eleven patients had dyspeptic symptoms at one time or another; barium meals were thought necessary in only two, and one of these showed a peptic ulcer. There were no cases of valvular or other heart lesions. The patient with psoriasis developed this at the age of 14 ; spinal symptoms began 18 years later when she was 32 , and 11 years after this the peripheral joints became affected. Now, 5 years later, she has typical psoriatic arthropathic changes in both hands and wrists. Apart from this patient, six others had symptoms or signs of involvement of peripheral joints consisting of swelling and tenderness of the hands, knees, and feet. 


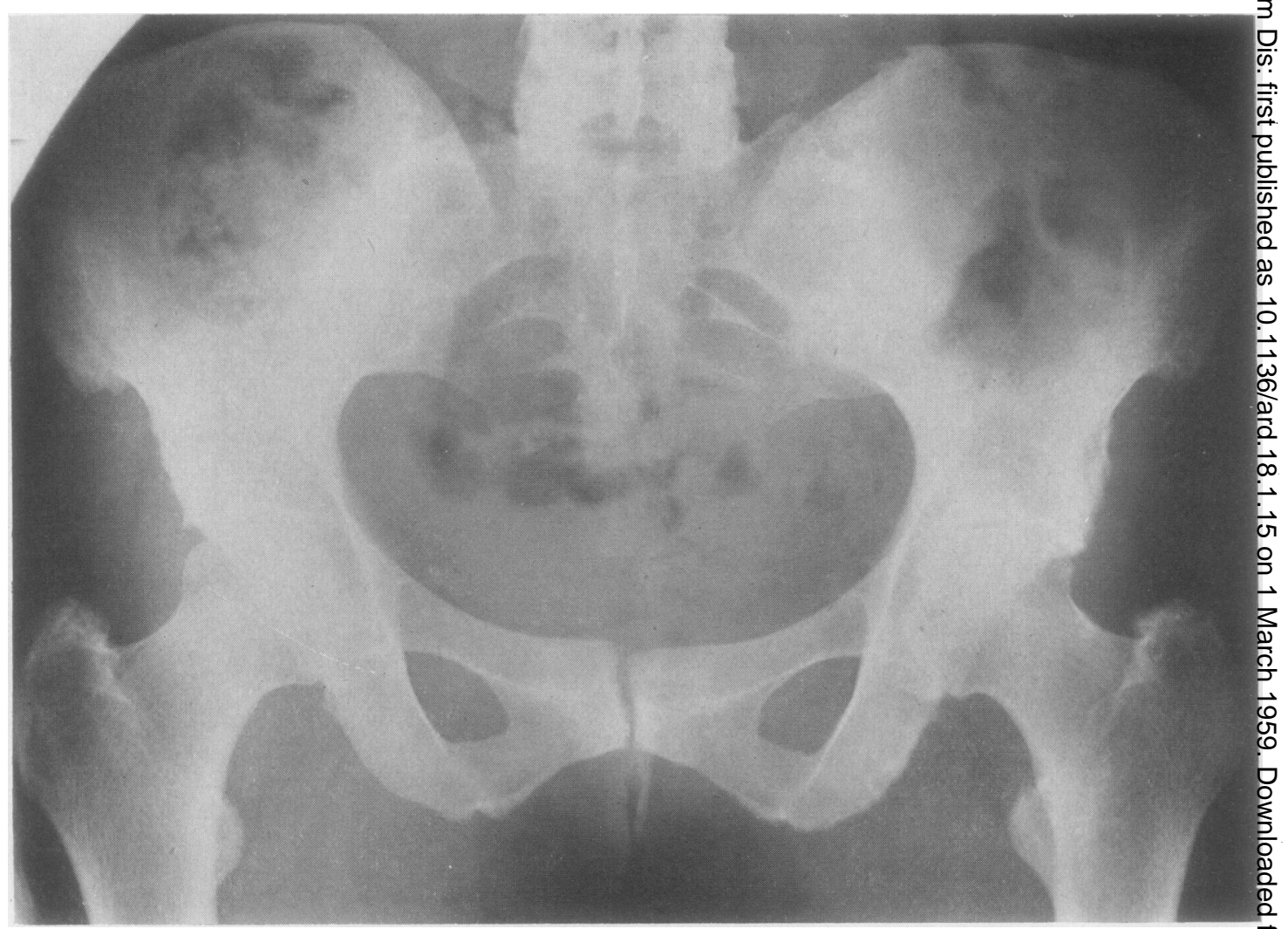

Fig. 6.-Feathery irregularity of outer surface of pelvis and both trochanters in a patient with psoriasis. There were also typical psoriatic $\overrightarrow{\overline{0}}$ changes in the hands: despite this radiotherapy produced an improvement in spinal symptoms which has lasted since it was given 102 years ago. (By courtesy of Dr. Michael Good.)

\section{Treatment and Course of Disease}

Eleven patients had one or more courses of radiotherapy applied to the spine; relief of pain for varying periods was obtained in six. Of fourteen given phenylbutazone, nine considered that it gave very satisfactory relief of both pain and stiffness and found it superior to the usual aspirin preparations. Side-effects from the drug occurred in two patients and were only of a minor nature.

Perhaps the most striking feature is the variable rate at which the spondylitis progresses. It may spread throughout the entire spine and result in the same advanced changes as are seen in men, with the characteristic forward stoop, loss of rib movement, and rigidity of the spine; five patients were affected to this extent. On the other hand it seems that such severe deformity is less likely to develop than in men, and more often than not the ankylosis is restricted to the pelvis even after many years. One such patient was a woman of 27 who had had the characteristic spinal symptoms for 12 years; she had also had five episodes of iritis. When examine she was found to have a reduced chest expansior? $\left(1 \frac{3}{4}\right.$ in.), raised erythrocyte sedimentation rate, an partly ankylosed sacro-iliac joints, but she retaine क्षु. good spinal movement (spondylometer $90^{\circ}$ ) ans good posture. Even when spinal fixation and deformity are present, patients are able to leac relatively normal lives with the help of analgesics The only patients who were at all disabled were the two with hip involvement; the case history of onf of these has already been given (Case 2), but in view of the importance of this complication the relevant details about the other are now given.

Case 3, a woman aged 22, when she developed spon dylitis while serving in the Forces, had low backache a\& her initial symptom, and radiographs showed ligamen $ळ$ tous calcification. In accordance with the accepted ${ }^{+}$ practice of the time she was put to rest in a plaster bed for 16 months. At the completion of this treatment the hips were fused and she needed the help of crutches $t \Phi$ walk. When she attended the Clinic for the first time 3 years later her posture was excellent, but radiograph 
showed complete bony ankylosis of the sacro-iliac joints and the hips, as well as extensive changes in the spine.

In Cases 2 and 3 it appears in retrospect that treatment by immobilization was largely responsible for the fixation of the hips.

\section{Discussion}

From the small series of cases seen and treated in the clinic at Westminster Hospital and other cases seen elsewhere in consultation, it appears that there is no great difference in this disease as it affects women as compared with men, but that it does on the whole seem to be milder and less likely to produce extensive spinal changes, and to be for this reason more likely to be overlooked. Nevertheless, severe spinal changes did occur in five of the thirty cases here analysed. The apparent onset in the hips noted in two of the patients is particularly dangerous, as in the past such cases have been regarded as tuberculous and treated accordingly. Prolonged immobilization is bad therapy for ankylosing spondylitis, as fusion and subsequent crippling occur rapidly; early mobilization under full analgesic cover, with steroid therapy if necessary, is the better and more logical course.

It is of interest that pregnancy and childbirth had relatively little effect on the course of the disease. There was neither the apparent remission so frequently seen in the rheumatoid patient, nor the subsequent relapse. The burden of extra domestic duties sometimes produced symptomatic aggravation after the baby was born, but the actual disease process remained much the same throughout pregnancy and puerperium. The one patient with psoriasis, now under the care of Dr. Michael Good of Aylesbury, may be considered by some workers as falling into a different category and therefore not comparable to the other cases reported. Time will show how many subdivisions of this disease there may be. This patient has been included to show how such a syndrome can change over the course of the years to another form, and also how $x$-ray therapy applied to an atypical case still appears to have produced a lasting remission in the spinal symptoms while the condition progressed in psoriatic form at the periphery.

Finally, it is painfully apparent, on looking through the case histories of these patients in the past, that those who were not diagnosed early, and therefore did not receive the mistaken immobilization therapy, did better than the others. The only really crippled patients in the series had both been treated by prolonged immobilization. Swaim (1939) emphasized this point in Boston 20 years ago, but it still seems necessary to underline his warning and draw attention again to this danger.

\section{Summary}

Some clinical and radiological features of thirty female patients with ankylosing spondylitis are described. This disease appears to run a milder course in women than in men, but a very variable rate of development is noted. Radiological abnormalities in the symphysis pubis were frequently seen. Bilateral lesions of the hip joints developed rapidly in two patients, and were the cause of severe disability; both had been treated by immobilization and this is regarded as having been responsible for the subsequent fixation of these joints. Pregnancy and childbirth had little effect on the course of the disease. The value of phenylbutazone for the relief of symptoms is stressed.

\section{REFERENCES}

Blumberg, B., and Ragan, C. (1956). Medicine (Baltimore), 35, 1. Forestier, J., Jacqueline, F., and Rotes-Querol, J. (1956). "Ankylosing Spondylitis", trans. A. U. Desjardins, p. 209. Thomas, Springfield, Ill.

Hart, F. D., Bell, A. C. H., and Organe, G. S. W. (1951). Ann. rheum. Dis., $10,54$.

- and Maclagan, N. F. (1955). Ibid., 14, 77.

Romanus, R. (1953). Acta med. scand., Suppl. 280.

Swaim, L. T. (1939). J. Bone Jt Surg., $21,983$.

Tyson, T. L., Thompson, W. A. L., and Ragan, C. (1953). Ann. rheum. Dis., 12, 40.

Wilkinson, M., and Bywaters, E. G. L. (1958). Ibid., 17, 209.

\section{Spondylarthrite ankylosante chez la femme}

RÉSUMÉ

On décrit quelques caractères cliniques et radiologiques de la spondylarthrite ankylosante chez trente femmes. Cette maladie semble suivre une évolution plus benigne chez la femme que chez l'homme, mais on note une vitesse de développement très variable. On nota des anomalies radiologiques fréquentes de la symphyse pubienne. Des lésions bilatérales de l'articulation de la hanche apparurent rapidement chez deux malades, causant une grave incapacité; les deux cas avaient été traités par l'immobilisation, à laquelle on attribue la fixation subséquente de cette articulation. L'effet de la grossesse et des couches sur l'évolution de la maladie fut minime. On souligne l'importance de la phénylbutazone dans le soulagement symptomatique.

\section{Espondílartritis anquilosante en mujeres}

\section{Sumario}

Se describen ciertos caracteres clínicos y radiológicos de la espondilartritis anquilosante en treinta enfermas. Esta enfermedad parece seguir una evolución más benigna en la mujer que en el hombre, pero la velocidad del desarrollo es muy variable. Anomalías radiológicas de la sínfisis púbica fueron frecuentes. Lesiones bilaterales de la articulación de la cadera aparecieron rápidamente en dos enfermas, causando incapacidad grave; ambos casos habían sido tratados con inmovilización, a lo que se atribuye la fijación consiguiente de esta articulación. La preñez y el parto tuvieron poco efecto sobre la evolución de la enfermedad. Se subraya la importancia de la fenilbutazona en el alivio sintomático. 